\title{
The role of diffusion tensor imaging tractography for Gamma Knife thalamotomy planning
}

\author{
*João Gabriel Ribeiro Gomes, MD,1,2 Alessandra Augusta Gorgulho, MD, MSc,1 \\ Amanda de Oliveira López, MD, ${ }^{2}$ Crystian Wilian Chagas Saraiva, MSc, ${ }^{1}$ \\ Lucas Petri Damiani, MSc, ${ }^{1}$ Anderson Martins Pássaro, Med Phys, ${ }^{1}$ João Victor Salvajoli, MD, PhD, ${ }^{1}$ \\ Ludmila de Oliveira Siqueira, MD, ${ }^{1}$ Bernardo Peres Salvajoli, MD, ${ }^{1}$ and \\ Antônio Afonso Ferreira De Salles, MD, PhD'
}

1'Department of Neurosurgery and Radiotherapy of the Hospital do Coração (HCOR Neurosciences), Gamma Knife Unit, São Paulo-SP, Brazil; and 2Department of Neurosurgery, Real Hospital Português, Recife-PE, Brazil

OBJECTIVE The role of tractography in Gamma Knife thalamotomy (GK-T) planning is still unclear. Pyramidal tractography might reduce the risk of radiation injury to the pyramidal tract and reduce motor complications.

METHODS In this study, the ventralis intermedius nucleus (VIM) targets of 20 patients were bilaterally defined using Iplannet Stereotaxy Software, according to the anterior commissure-posterior commissure (AC-PC) line and considering the localization of the pyramidal tract. The 40 targets and tractography were transferred as objects to the GammaPlan Treatment Planning System (GP-TPS). New targets were defined, according to the AC-PC line in the functional targets section of the GP-TPS. The target offsets required to maintain the internal capsule (IC) constraint of < 15 Gy were evaluated. In addition, the strategies available in GP-TPS to maintain the minimum conventional VIM target dose at $>100$ Gy were determined.

RESULTS A difference was observed between the positions of both targets and the doses to the IC. The lateral $(x)$ and the vertical (z) coordinates were adjusted $1.9 \mathrm{~mm}$ medially and $1.3 \mathrm{~mm}$ cranially, respectively. The targets defined considering the position of the pyramidal tract were more medial and superior, based on the constraint of 15 Gy touching the object representing the IC in the GP-TPS. The best strategy to meet the set constraints was $90^{\circ}$ Gamma angle (GA) with automatic shaping of dose distribution; this was followed by $110^{\circ} \mathrm{GA}$. The worst GA was $70^{\circ}$. Treatment time was substantially increased by the shaping strategy, approximately doubling delivery time.

CONCLUSIONS Routine use of DTI pyramidal tractography might be important to fine-tune GK-T planning. DTI tractography, as well as anisotropy showing the VIM, promises to improve Gamma Knife functional procedures. They allow for a more objective definition of dose constraints to the IC and targeting. DTI pyramidal tractography introduced into the treatment planning may reduce the incidence of motor complications and improve efficacy. This needs to be validated in a large clinical series.

http://thejns.org/doi/abs/10.3171/2016.7.GKS161553

KEY WORDS Gama Knife; thalamotomy; tremor; thalamus; tractography; anisotropy; stereotactic radiosurgery

S TEREOTACTIC radiosurgery has the capability of creating a virtually noninvasive focal lesion in the brain. Functional disorders are approximately $5 \%$ of diseases treated with radiosurgery. ${ }^{13}$ Radiosurgical Gamma Knife thalamotomy (GK-T) for refractory tremor has been performed in more than 900 patients worldwide. ${ }^{5} \mathrm{Al}-$ though considered a safe and well-tolerated treatment, it can cause adverse events. 5,21,26,28,30,41,43 Motor problems are one of the most feared complications; they occur in approximately $8 \%$ of patients treated, and a method to control tremor has not been perfected. , $20,44^{2}$

A recent review of the literature concerning GK-T

ABBREVIATIONS AC-PC = anterior commissure-posterior commissure; $A S T=$ adjust shaped target $; \mathrm{AT}=$ adjusted target; $\mathrm{DSF}=$ dynamic shaping function; $\mathrm{DTI}=$ diffusion tensor imaging; GA = Gamma angle; GK-T = Gamma Knife thalamotomy; GP-TPS = GammaPlan Treatment Planning System; IC = internal capsule; OT = original target; $\mathrm{VIM}=$ venetralis intermedius nucleus.

SUBMITTED June 10, 2016. ACCEPTED July 26, 2016.

INCLUDE WHEN CITING DOI: 10.3171/2016.7.GKS161553.

* Drs. Gomes, Gorgulho, and De Salles contributed equally to this work. 
shows that approximately $80 \%$ of patients can expect to receive some clinical benefit from the procedure for refractory tremor. Adverse events reported by many authors ranged from $0 \%$ to $16 \% .{ }^{5}$ Complications include contralateral numbness, hemiparesis, dysphagia, and death. Many factors are involved in complications, such as target location, prescribed dose, internal capsule proximity of the isocenter, and patient characteristics, which are still not clearly defined. For example, preexisting vasculopathy, previous surgery, and previous irradiation are believed to be risk factors. Actually, the patients with these comorbidities, at risk from conventional surgery, are chosen for radiosurgery. ${ }^{11,20}$ Specifically for these patients, it is important to reduce complications with additional strategies and enhance safety with a proper definition of the regions at risk.

Diffusion tensor imaging (DTI) tractography reconstruction of the pyramidal tract based on anisotropy is increasingly being used in stereotactic functional surgery. Visualization of functional targets is now a reality using these MRI techniques. $7,15,33,35,37$ Moreover, connectivity from these targets to other areas of the brain affected by these targets is now possible., ${ }^{2,25}$ Particularly in GK-T, its addition to the planning could help to avoid motor injury, resulting in an even safer treatment and a more effective procedure. Herein, these possibilities are evaluated in a strictly theoretical study using images of patients undergoing a variety of functional neurosurgery procedures in our service. The purpose of the study was to develop a means of transferring DTI tractography into GammaPlan and to improve information available on planning strategies for a safe GK-T.

\section{Methods \\ Patient Population}

Twenty patients serially treated at our institution between 2013 and 2016, under MRI guidance and undergoing functional stereotactic procedures for diverse diagnoses, were included in this study (Table 1). Our institutional review board approved the use of the images. Patients underwent surgery for different diagnoses, including obsessive-compulsive disorders, essential tremor, Parkinson's disease, morbid obesity, and dystonia. Patients underwent deep brain stimulation implants in the subthalamic nucleus, hypothalamus, ventralis intermedius nucleus (VIM), or globus pallidus interna, VIM GK-T, and GK-anterior capsulotomy. The mean age was 51 years (range 20-80 years; Table 1). Forty cerebral hemispheres were analyzed.

\section{MRI Acquisition}

Magnetic resonance imaging was obtained before the procedures without a stereotactic frame to avoid artifacts in the DTI. A GE 1.5-T intraoperative MRI machine was used on all patients to obtain sequences with and without contrast, (T1 volumetric $1 \mathrm{~mm}$, FLAIR, and T2 $1 \mathrm{~mm}$ ). DTI data were acquired using dual spin-echo echo-planar imaging (TR 11,500 msec, TE 88.6-209 msec [optimized], acquisition matrix $254 \times 254$, field of view 25.0 $\mathrm{cm})$. A slice thickness of $1 \mathrm{~mm}$ with no gap was used. Diffusion-sensitizing gradient encoding was applied in 33
TABLE 1. Population characteristics

\begin{tabular}{lc}
\hline \multicolumn{1}{c}{ Variables } & Values \\
\hline No. of patients & 20 \\
\hline No. of hemispheres & 40 \\
\hline Age (yrs) & 51 \\
\hline Mean & $20-80$ \\
\hline Range & \\
\hline Sex & 13 \\
\hline Male & 7 \\
\hline Female & 3 \\
\hline Diagnosis & 6 \\
\hline Obsessive-compulsive disorder & 2 \\
\hline Morbid obesity & 1 \\
\hline Essential tremor & 8 \\
\hline Dystonia & \\
\hline Parkinson's disease & 24 \\
\hline Tractography quality & 10 \\
\hline Excellent & 6 \\
\hline Good &
\end{tabular}

directions by using a diffusion-weighted factor $(b=750$ $\mathrm{sec} / \mathrm{mm}^{2}$ ), and 1 image was acquired without the use of a diffusion gradient, i.e., $\mathrm{b}=0 \mathrm{sec} / \mathrm{mm}^{2}$. The DTI time was approximately 8 minutes.

\section{Anisotropy and Tractography With Transfer to GammaPlan}

Tractography was reconstructed using Iplannet 3.0 stereotaxy software (BrainLAB). The fractional anisotropy threshold was between 0.2 and 0.35 , and minimum length was between 75 and $100 \mathrm{~mm}$. Regions of interest were placed in the precentral gyrus, the brainstem, and the posterior internal capsule (IC) limb. The fibers in common with these regions of interest were tracked (Fig. 1). Fibers in excess that were not pyramidal tract fibers were removed, based on known anatomy, leaving pure pyramidal tract fibers "en passage" close to the thalamic target, the VIM. Bilateral pyramidal tracts were transformed into 3D objects and imported into the GammaPlan Treatment Planning System (GP-TPS) using Patxsfere R.T. 1.56 Software (BrainLAB). IC objects were classified as organ at risk in the GP-TPS (Fig. 2). Tractography quality was graded as excellent, good, or poor, according to the correlation between tractography, anisotropy, and conventional anatomy of the pyramidal tract.

\section{Stereotactic Radiosurgical Thalamotomy Planning}

Using images in the GP-TPS, the anterior commissure-posterior commissure (AC-PC) line was defined with the software's function and checked in 3 Cartesian planes crossing the AC-PC line, i.e., coronal, sagittal, and axial. Using the functional target section of the GP-TPS, the VIM target was defined. The $\mathrm{x}$ (lateral), $\mathrm{y}$ (anteroposterior), and $\mathrm{z}$ (craniocaudal) coordinates in relation to the AC-PC line were planned as previously reported by our 

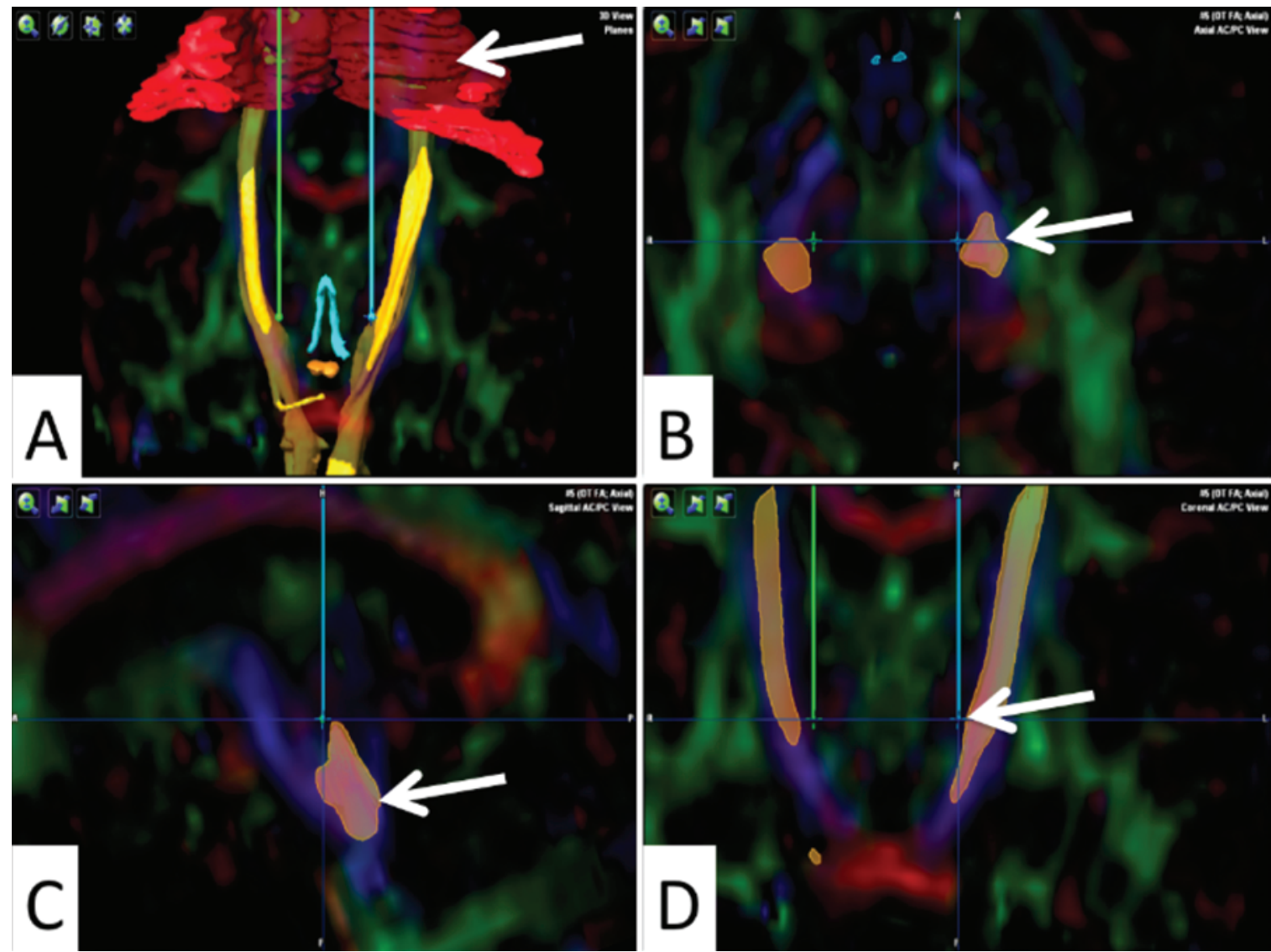

FIG. 1. Deterministic tractography technique. Object creation: Regions of interest cortex (A, arrow), IC (B, arrow), and brainstem (C, arrow). The length of the fibers was $75-100 \mathrm{~mm}$, there were 33 directions, and the fractional anisotropy (FA) threshold was $0.2-0.35$. The target in relation to the IC is represented in $\mathbf{D}$ (crosses; arrow).

group $^{4,29}$ and other authors ${ }^{21,26,28}: \mathrm{x}=11 \mathrm{~mm}$ from the lateral border of the third ventricle, $\mathrm{y}=25 \%$ of the AC-PC line posterior $+1 \mathrm{~mm}$ anterior, and $\mathrm{z}=2.5 \mathrm{~mm}$ above the AC-PC line. The GK-T was planned with a 4-mm collimator centered in the functional target cross, with a maximum dose of $120 \mathrm{~Gy}$. The minimum distance from the isocenter to IC was measured (Fig. 2). Plans with $70^{\circ}$, $90^{\circ}$, and $110^{\circ}$ gamma angle (GA) were simulated, and the maximum dose reaching IC was recorded, as were $10 \mathrm{~Gy}$ volumes, 12 Gy volumes, and 15 Gy volumes (Table 2). Time of treatment was also evaluated.

\section{Automatic Shaping}

The Grade 1 dynamic shaping function (DSF) of the GK-TPS was used to spare the IC from receiving a $15 \mathrm{~Gy}$ dose. Again, plans with $70^{\circ}, 90^{\circ}$, and $110^{\circ} \mathrm{GA}$ were simulated, and doses reaching IC were evaluated, with volumes of $10 \mathrm{~Gy}, 12 \mathrm{~Gy}$, and $15 \mathrm{~Gy}$ recorded. Time of treatment was also assessed.

\section{Adjusted Target}

The adjusted target (AT) was obtained by moving away from the original target (OT) when the 15 Gy isodose line reached the IC. Movements were only in x (medial) and $\mathrm{z}$ (cranial) directions. The adjustment in each coordinate was the minimum necessary to permit a 15 Gy isodose line to just touch the IC. The minimum distance from the center of the AT to the IC was measured. Again, the isodose most favorable was defined by studying the GAs $70^{\circ}$, $90^{\circ}$, and $110^{\circ}$. The Leksell stereotactic frame was adjusted parallel to the AC-PC line based on Reid's line, the infraorbital meatal line. Therefore, the $90^{\circ} \mathrm{GA}$ was the most comfortable for the patient. The $10 \mathrm{~Gy}, 12 \mathrm{~Gy}$, and $15 \mathrm{~Gy}$ volumes covering the IC were recorded. Time of treatment was also assessed. The difference between the OT and the AT in $\mathrm{x}$ and $\mathrm{z}$ directions was noted, and distance was calculated based on the Euclidian formula (Fig. 2C). The dose that the OT received from the AT was recorded. A minimum dose $>100$ Gy was accepted as the dose required to achieve clinical benefit. The plans reaching these requirements were called eligible (Table 2).

\section{Adjusted Target and Shaped Dose}

Further improvement of dose distribution in relation to the IC was obtained with Grade 1 DSF and movement from the OT to the adjusted shaped target (AST). The AST was achieved by moving from the AT in $\mathrm{x}$ and $\mathrm{z}$ directions as necessary to permit the constraint of $15 \mathrm{~Gy}$ to the IC. GK-T with $90^{\circ}$ and $110^{\circ} \mathrm{GA}$ was planned, and the maximum dose to the IC, as well as the 10,12, and 15 Gy volumes reaching the IC were recorded. The minimum distance from the center of the target to the IC was 

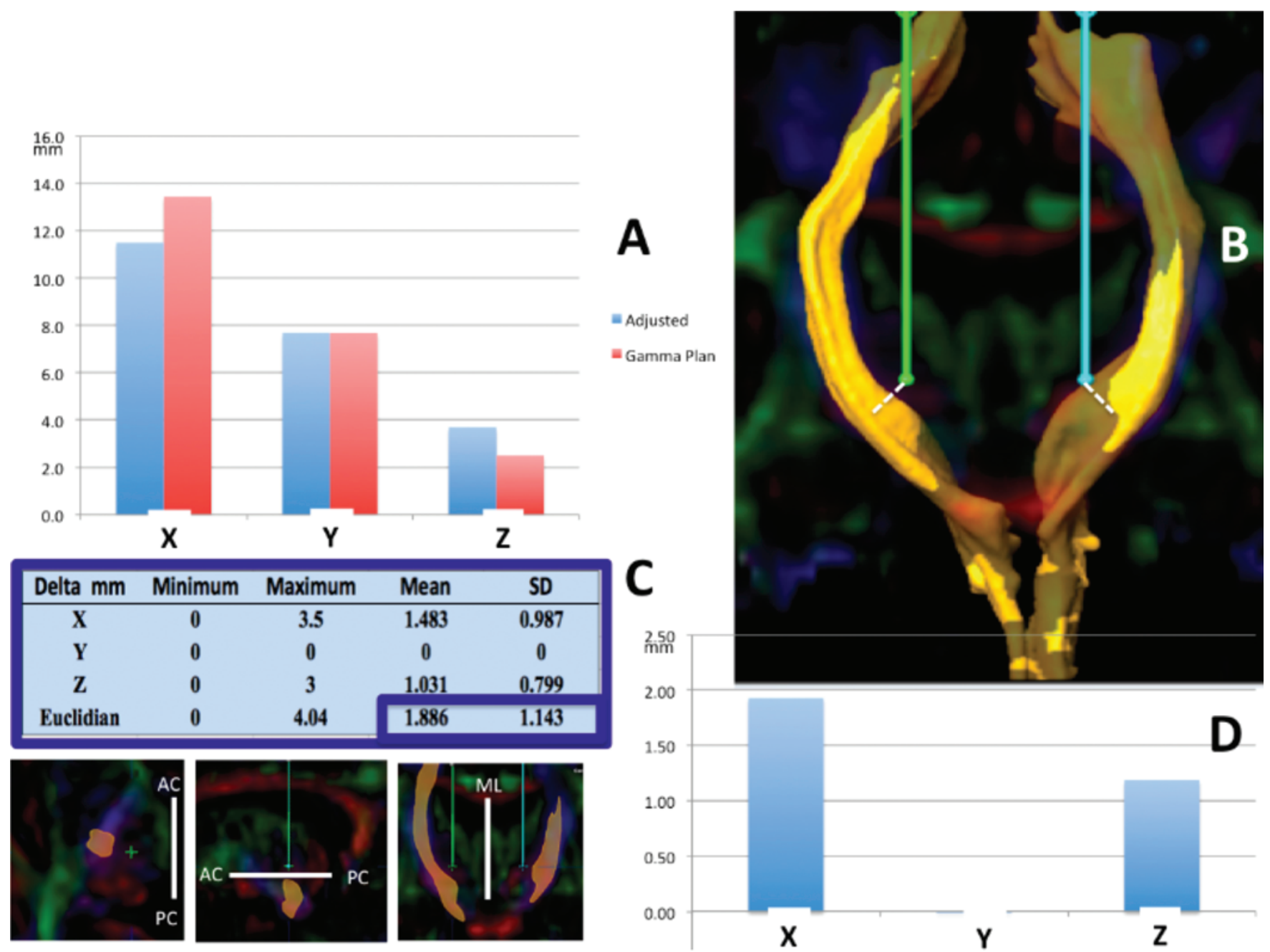

\begin{tabular}{|ccccc|}
\hline Delta mm & Minimum & Maximum & Mean & SD \\
\hline $\mathrm{X}$ & 0 & 3.5 & 1.483 & 0.987 \\
$\mathrm{Y}$ & 0 & 0 & 0 & 0 \\
$\mathrm{Z}$ & 0 & 3 & 1.031 & 0.799 \\
Euclidian & 0 & 4.04 & 1.886 & 1.143 \\
\hline
\end{tabular}
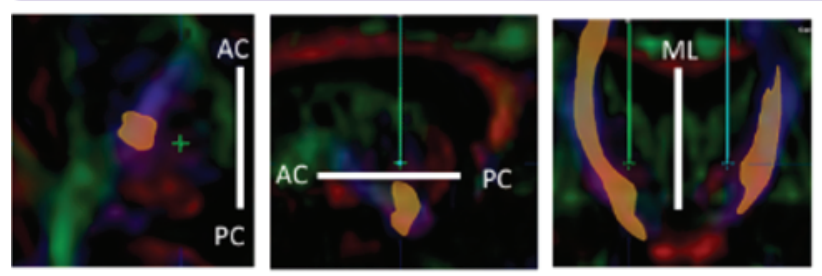

FIG. 2. Graphs $A$ and $D$ show the magnitude of changes in $x, y$, and $z$ coordinates. Notice that there were no changes in the $y$ coordinate (D), whereas the magnitude of changes in the $x$ coordinate was greater than that in the $z$ coordinate (A). B: The dashed white line shows the distance of the target to the IC in 3D, revealing that the $x$ and $z$ directions are the ones that avoid the IC at the VIM level. C: The table shows the magnitude of the changes in $x$ and $z$ in relation to the OT and AST. The anisotropy from right to left shows axial, sagittal, and coronal planes with the AC-PC line defined; the VIM is visualized here. ${ }^{38}$

measured. The time of treatment was also assessed. The difference between the original target and the AST in $\mathrm{x}$ and $\mathrm{z}$ directions was noted. The dose that the OT received from the plan at the AST was evaluated. A minimum dose $>100$ Gy was accepted as the dose required to achieve clinical benefit.

\section{Statistical Analysis}

Continuous variables were determined using generalized least squares to adequate models for repeated measures per patient and heteroscedasticity between groups (shaped/not shaped, and angle) considering interactions between angle, shape, and target. ${ }^{32}$ A 5\% significance level

TABLE 2. Doses reaching the IC when using the conventional target obtained with the GammaPlan compared with the strategies to spare the IC

\begin{tabular}{|c|c|c|c|c|c|c|c|c|c|c|}
\hline \multirow[b]{2}{*}{ Variable } & \multicolumn{3}{|c|}{$\begin{array}{c}\text { Conventional Location, } \\
\text { Not Shaped }\end{array}$} & \multicolumn{2}{|c|}{$\begin{array}{l}\text { Conventional, } \\
\text { Location Shaped }\end{array}$} & \multicolumn{3}{|c|}{$\begin{array}{l}\text { Adjusted Target } \\
\text { Location }\end{array}$} & \multicolumn{2}{|c|}{$\begin{array}{l}\text { Adjusted Target } \\
\text { Location, Shaped }\end{array}$} \\
\hline & GA $70^{\circ}$ & $\mathrm{GA} 90^{\circ}$ & $\mathrm{GA} 110^{\circ}$ & $\mathrm{GA} 90^{\circ}$ & GA $110^{\circ}$ & $\mathrm{GA} 70^{\circ}$ & $\mathrm{GA} 90^{\circ}$ & GA $110^{\circ}$ & $\mathrm{GA} 90^{\circ}$ & $\mathrm{GA} 110^{\circ}$ \\
\hline Maximal dose to IC (Gy) & 39.46 & 37.86 & 37.64 & 36 & 35.15 & 16.98 & 15.57 & 15.08 & 15.09 & 15.08 \\
\hline 10 Gy capsule volume $\left(\mathrm{mm}^{3}\right)$ & 133.86 & 121.64 & 118.43 & 54.96 & 52.6 & 35.98 & 26.62 & 22.33 & 9.58 & 10.93 \\
\hline 12 Gy capsule volume $\left(\mathrm{mm}^{3}\right)$ & 88.90 & 77.61 & 78.98 & 37.6 & 36.01 & 13.44 & 8.2 & 5.85 & 2.84 & 2.98 \\
\hline 15 Gy Capsule volume $\left(\mathrm{mm}^{3}\right)$ & 51.47 & 45.82 & 45.28 & 22.93 & 22.43 & 2.33 & 0.61 & 0.07 & 0.06 & 0.05 \\
\hline$\%$ Eligible & \multicolumn{3}{|c|}{12.5} & \multicolumn{2}{|c|}{20} & \multicolumn{3}{|c|}{27.5} & \multicolumn{2}{|c|}{65} \\
\hline
\end{tabular}




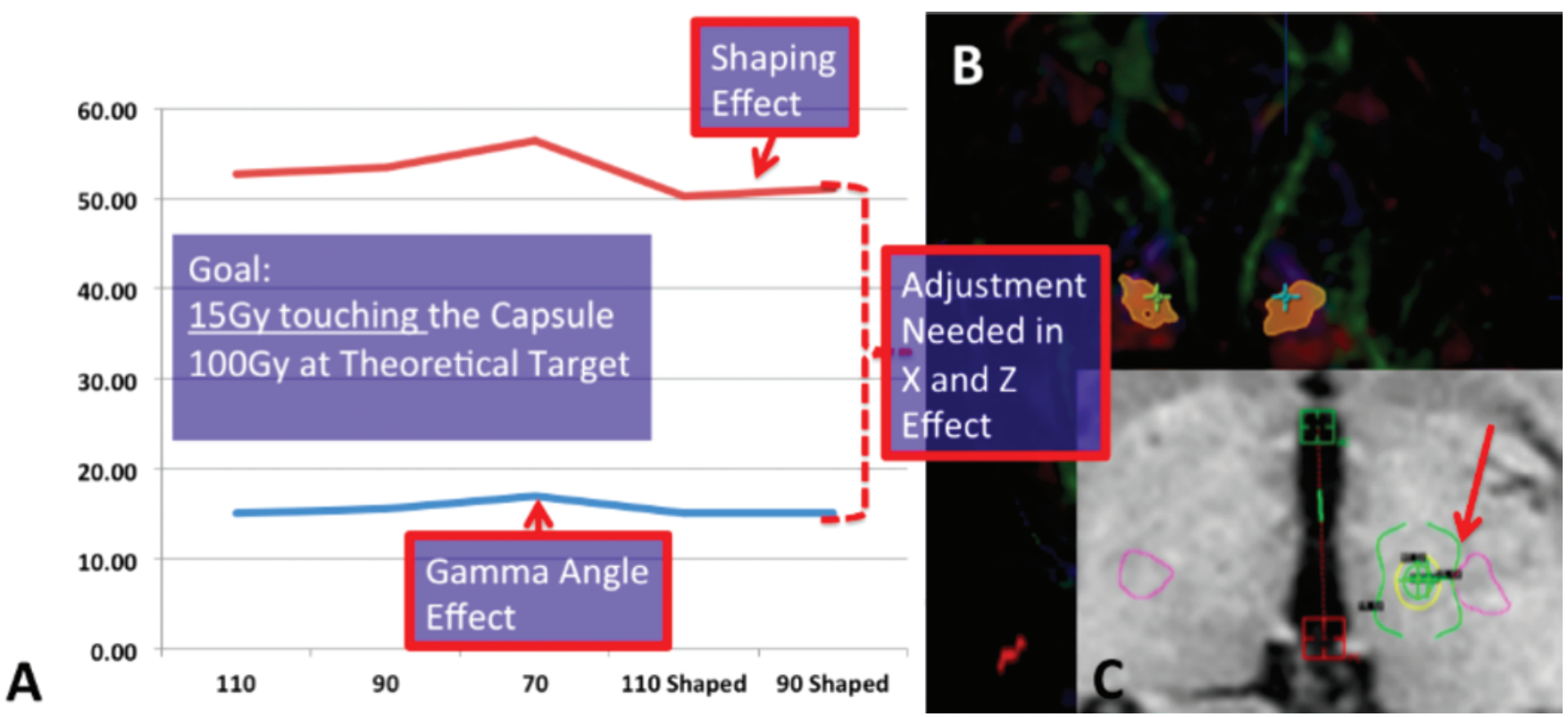

FIG. 3. A: Graph showing a summary of the doses to the IC with the adjustment of the target and angles, as well as shaping of the dose. B: An example for which the target is on the line of the IC, as defined by tractography superimposed in the anisotropy. C: An example of the ideal situation with the shaping of the dose and movement of the target to avoid the IC. The arrow shows the $15 \mathrm{~Gy}$ line shaped to avoid the IC. The graph in A shows that the best scenarios are with the movement of the target using either a $100^{\circ}$ or $90^{\circ} \mathrm{GA}$. The worst scenario was with the $70^{\circ} \mathrm{GA}$. The Leksell stereotactic frame is adjusted parallel to the AC-PC line based on Reid's line. Therefore, the $90^{\circ} \mathrm{GA}$ is the most comfortable for the patient.

was used, and tests were performed with R software (version 3.2.3, R Core Team, 2015).

\section{Results}

Only 5 of the 40 plans based on the conventional VIM target provided by the GammaPlan software (OT) delivered $<15$ Gy to the internal capsule (12.5\%). This was based on the isolated tractography object in GammaPlan as a reference of pyramidal tract limits. To avoid a $>15$ Gy dose to the IC, in 26 of the 40 plans a dose $>100$ Gy to the VIM was prescribed (65\%). The best sparing IC dose, prescribing at least 100 Gy to the VIM, was the adjusted target with shaped distribution (ATS) using a $90^{\circ}$ Gamma angle. The second best strategy was ATS with $110^{\circ} \mathrm{GA}$ (Fig. 3). The $70^{\circ} \mathrm{GA}$ was the worst strategy; therefore, it was not studied further (Figs. 4 and 5). Figure 5 shows that the best strategy that permitted $>100$ Gy to the OT was $90^{\circ}$ with shaping of the dose (Fig. 5A). The automatic shaping used to decrease the dose to the IC increased substantially and significantly at the time of treatment $(\mathrm{p}<$ 0.05; Fig. 5B).

\section{Dose Delivered to the IC}

When the target defined by the GK-TPS was analyzed without any strategy for improving the dose to the IC, high-level doses were reached (Table 2). The significance of each of these doses in the IC has not yet been defined in clinical series available in the literature. The strategies used in this study aimed at not allowing 15 Gy to reach the IC were decided upon as a matter of safety (Fig. 3C). It was possible in $65 \%$ of cases ("Eligible," Table 2) to achieve the constraints proposed. Table 2 shows the con- tribution of each strategy available in the GK-TPS to decrease the spillage of the dose in the IC.

\section{Gamma Angle}

The GA $110^{\circ}$ treatments were associated with lower doses to the IC, then the $90^{\circ}$, followed by the $70^{\circ}$ (Table 2 ). These values were improved with movement of the target and shaping of the dose. Figures 3 to 6 show the participation of the GA in dose distributions; it had a modest, but visible, effect. The GA also had a very modest effect on treatment time. These values of time differences are not clinically significant (Fig. 5B).

\section{Target Changes}

Coordinate changes ( $\mathrm{x}$ and $\mathrm{z}$ ) were the most effective strategy to avoid higher doses to the IC. Figure 2 shows the magnitude of movements and the OT versus AST distance from the midline and superior to the AC-PC plan. The vector change-sparing IC is shown in the $3 \mathrm{D}$ representation of the IC (Fig. 2B). The median difference in the $\mathrm{x}$ coordinate was $1.5 \mathrm{~mm}$ medially and 1.0 cranially for the AT compared with the OT, for a median Euclidian distance of $1.9 \pm 1.3 \mathrm{~mm}$ (Fig. 2C). Without shaping dose distribution, a median 6-mm distance from the IC (range $4.3-7.1 \mathrm{~mm}$ ) was needed to achieve $<15$ Gy to the IC, substantially distant from the OT. Figure 3 summarizes all changes needed.

\section{Dose Volume}

The volumes of the IC theoretically receiving $10 \mathrm{~Gy}$ and 12 Gy are shown in Fig. 6. The significance of these values requires validation. To ensure safety in treatment, 


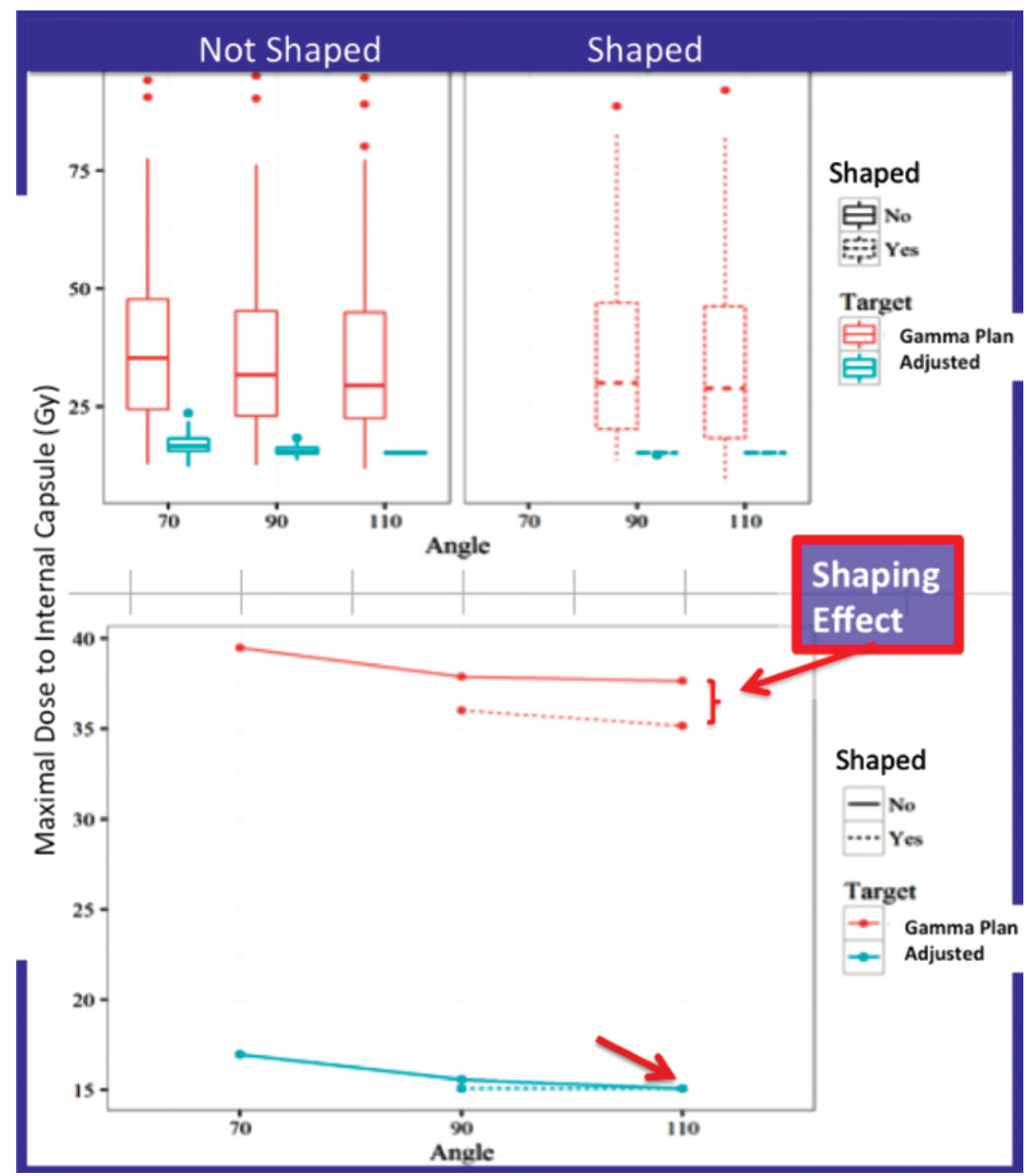

FIG. 4. The distribution best sparing the IC was the one shaped at the adjusted target. The difference between GA $90^{\circ}$ and $110^{\circ}$ was not significant, which was evident when the shaping function was used (arrow). See the effect of shaping in the original target. This effect is not seen in the adjusted target (bottom arrow).

we strived to obtain plans permitting the 15 Gy isodose line to touch the border of the IC, without encompassing it. Figure 6 denotes that the $90^{\circ}$ and $110^{\circ}$ GAs yield this constraint satisfactorily. Table 2 shows that using all the strategies necessary to spare the IC from receiving $15 \mathrm{~Gy}$ provided $100 \mathrm{~Gy}$ in only $65 \%$ of the patients. Therefore, compromises need to be made based on knowledge of the anatomy and the experience of the radiosurgery team treating the patient, taking into consideration all comorbidities that the patient has faced with the dose of radiation provided to the IC.

\section{Discussion}

This study shows that careful attention to planning should be taken to develop safe treatment for patients with uncontrollable tremor when using the Gamma Knife technique. There are, however, enough strategies available to achieve this goal. The use of DTI with its provided anisotropy and tractography are helpful in this exercise, progressively becoming an important part of these strategies. As this technique is brought into stereotactic surgery, $2,33,35,37 \mathrm{a}$ better understanding of its value will be achieved. There is an increased interest in tractography in targeting, although the limitations are still not completely understood.,.$^{3,23,27}$ It becomes clear from this theoretical study that an objective definition of the pyramidal tract to guide dose distribution manipulation is possible. The introduction of a better definition of IC might improve the results and decrease complications, which is already acknowledged and described extensively in the literature. $8,10,20,30,44$

Arbitrarily and theoretically, we set 15 Gy as the maximal dose we would allow to touch the medial border of the IC to have a safe GK-T plan. This is a very safe approach, because there is no clear guidance in the literature on the safest dose tolerated by the IC. Authors describing their 

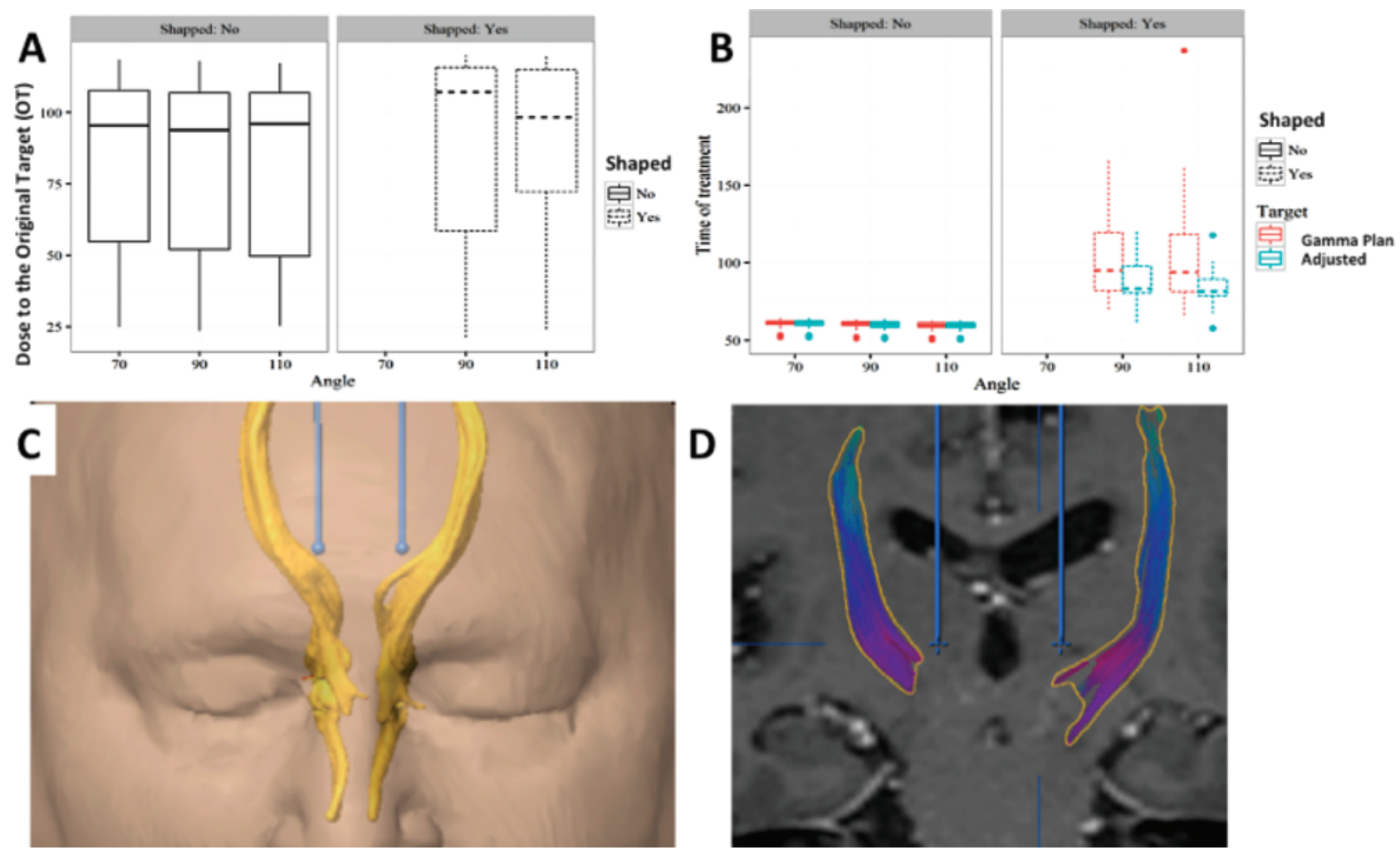

FIG. 5. A: Graph showing the best strategy for obtaining a dose above 100 Gy to the OT is the shaped distribution using the $90^{\circ} \mathrm{GA}$, although the $110^{\circ}$ was more consistent. B: Graph showing that the shaping substantially increased the time of treatment. C and D: Image showing the ideal 3D distance of the target from the pyramidal tract $(C)$, and the pyramidal tract in 2 dimensions showing the ideal $(\mathrm{x})$, and distance (D).
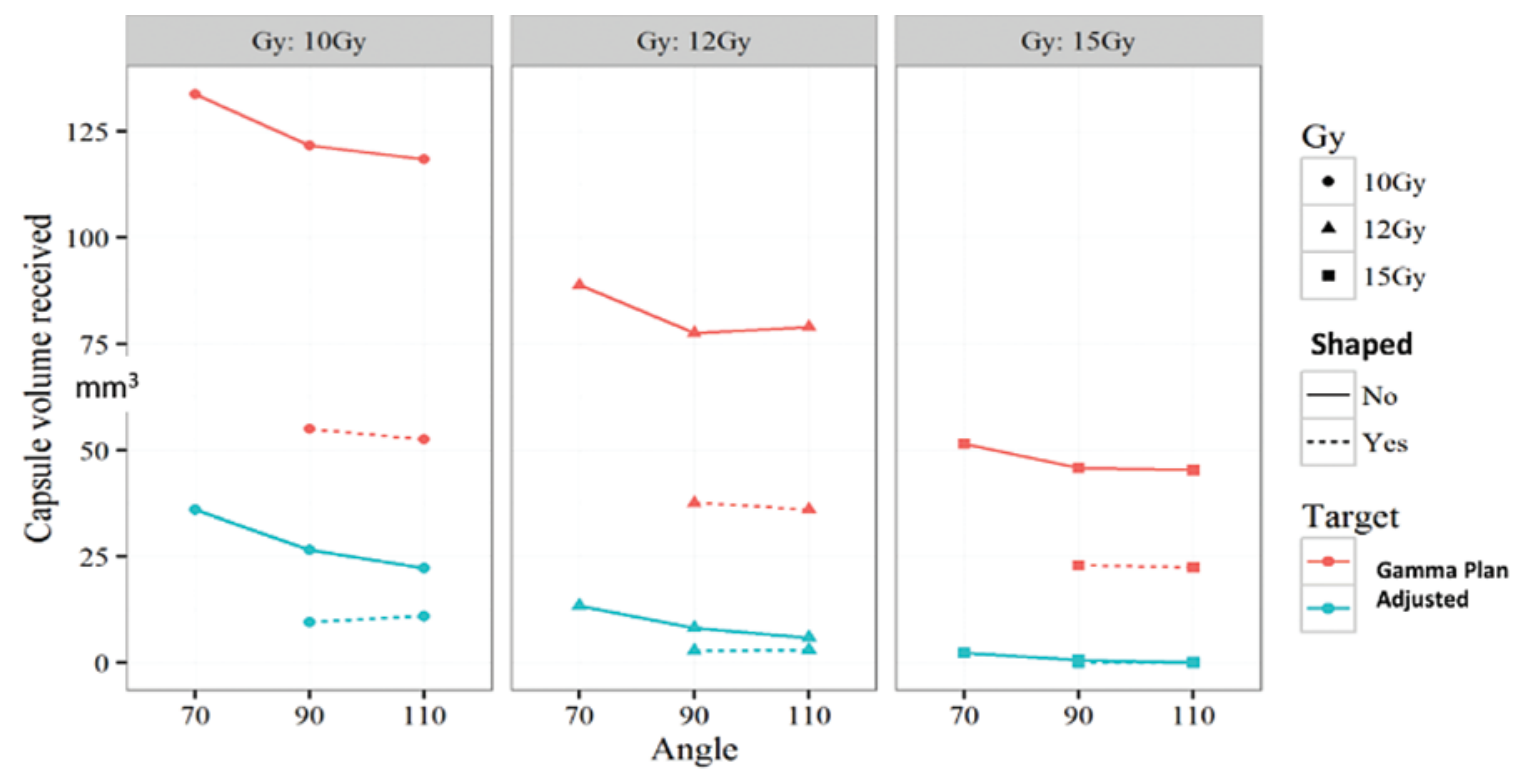

FIG. 6. These graphs show the volume of the IC receiving 10, 12, and $15 \mathrm{~Gy}$. The strategies available in the GammaPlan were used to achieve < $15 \mathrm{~Gy}$ in the IC as shown in the graph on the far right side. The red continuous line shows the dose delivered to the IC without strategies, using the theoretical coordinates. The dashed red line denotes the addition of the autoshaping capabilities of GammaPlan. The blue continuous line denotes the effect of the adjustments of $x$ and $y$ coordinated and the final result with all the strategies. Here the dose that reaches the IC is < $15 \mathrm{~Gy}$ when the angle of treatment is also optimized. The effect of the angle is shown in all 3 graphs $(10,12$, and $15 \mathrm{~Gy})$. 
plan have used a more aggressive approach, allowing 15 Gy to reach the center of the IC.22 This study shows that by using the conventional indirect target to reach the VIM and obeying our defined constraints, only $5(12.5 \%)$ of 40 plans delivered $\mathrm{a}<15$ Gy maximum dose to the medial border of the IC when an indirect target with the conventional coordinates was used. Therefore, taking advantage of all the strategies available in the GP-TPS, as well as the changes in the target, without compromising the effectiveness of the treatment is important.

Lefranc et al. importing fraction anisotropy colored maps into GP-TPS suggests allowing 15 Gy to reach the center of what is represented as IC in their maps. ${ }^{22}$ That constraint is more audacious than the one presented in this study, in which we accepted 15 Gy reaching the medial border of IC. Unfortunately, Lefranc et al. did not present clinical results in their technical paper describing targeting; however, in a recent publication, the same group reported that in 50 patients treated with their usual protocol and followed by a multiinstitutional prospective evaluation, only 1 patient experienced side effects. This side effect was a transient hemiparesis associated with excessive edema around the thalamotomy site ${ }^{41}$ therefore causing pressure in the IC. Other authors have encountered more serious complications with GK-T, including hemiplegia and death..$^{20,31,45}$ This draws attention to the importance of improving the procedure by taking advantage of modern imaging. The acceptance of modification of established techniques meets resistance from traditional medicine, especially in surgical specialties in which a surgeon's adventures with new methods can be catastrophic for patients. A pertinent example is the acceptance by stereotactic surgeons of the incorporation into their practice of a direct target based on exquisite MRI images. ${ }^{6,14}$ Even today, we have colleagues who still insist on using ventriculography to perform functional neurosurgical procedures.

In this report, the coordinates of the VIM nucleus used were $\mathrm{x}=11 \mathrm{~mm}$ from the lateral border of the third ventricle, $\mathrm{y}=25 \%$ of the AC-PC line plus $1 \mathrm{~mm}$ anterior to the $\mathrm{PC}$, and $\mathrm{z}=2.5 \mathrm{~mm}$ above the AC-PC plane. Ohye et al. reported coordinates of the VIM nucleus as $\mathrm{x}=2 \mathrm{~mm}$ inside the thalamus external boundary $(15-17 \mathrm{~mm}$ from the midline), $\mathrm{y}=7 \mathrm{~mm}$ anterior to posterior commissure, and $\mathrm{z}=3-4 \mathrm{~mm}$ superior to AC-PC line. ${ }^{30}$ In other reports, ${ }^{20,44}$ target coordinates were $\mathrm{x}=11 \mathrm{~mm}$ lateral to the wall of the 3rd ventricle ( $13 \mathrm{~mm}$ lateral of midline), $\mathrm{y}=6-8 \mathrm{~mm}$ anterior to $\mathrm{PC}$, and $\mathrm{z}=2-4 \mathrm{~mm}$ superior to the AC-PC plane. The choice of the dose in this study was based on a review of the recent literature, which denotes a progressive decrease in thalamotomy dose. All calculations were made with a point dose of $120 \mathrm{~Gy}$. As previously reported by Kihlstrom et al., radiosurgical lesions appear with at least 110 Gy with a 4-mm collimator. ${ }^{18}$ Radiation dose used in GK-T varies among previous reports from 120 to $180 \mathrm{~Gy} .{ }^{8,20,30,45}$

Adjusting the position of the target more medially and cranially proved to be the most effective strategy to avoid high doses to the IC. This leads to compromise of the location of the higher dose to the target, as shown in this study. Movement of the target to an acceptable location led to a decrease in dose of two-tenths order of magnitude in the IC, although not enough to allow 15 Gy to just touch the IC. Additionally, it was necessary to shape the dose distribution. Subtle changes in the VIM when GK-T is performed were already suggested by the pioneering authors of the technique, ${ }^{8,30,45}$ who had to progressively decrease the dose used to achieve acceptable results. ${ }^{30}$

Plugging techniques, ${ }^{22,40}$ before a laborious strategy, have become automatic since the Gamma Knife Perfexion (Elekta, Inc.) was introduced. This study used the Grade 1 DSF of the GP-TPS to improve dose distribution according to the location of the IC. Even with the availability of Grades 2 and 3, this advanced plugging did not achieve sparing of the IC; in fact, this was generally not possible without compromising the location of the target unacceptably. The automatic shaping function was able to decrease the dose to the capsule only by 1 decimal order of magnitude; it allowed a substantial dose to be delivered to the target, i.e., more than $100 \mathrm{~Gy}$ in at least $40 \%$ more patients (Table 2). Therefore, although not as effective for sparing the IC as the movement of the target, it was very effective in providing the desired dose to the target, denoting the importance of this strategy when performing functional procedures with a Gamma Knife unit.

The time of treatment is definitely affected by doseshaping techniques. The importance of treatment time is less clear and might be difficult to determine, mostly for large doses. ${ }^{9}$ It is speculated that time of treatment may have a biological effect, mostly when the time cannot be adjusted, as is the case with the use of decayed ${ }^{60} \mathrm{Co}$ sources. ${ }^{1}$ There is no clear answer to this speculation. It is, however, important in terms of patient comfort, although patients tolerate 1 to 2 hours of treatment well without needing to break the continuity of the procedure. In this study, the total treatment time using all the strategies did not surpass 2 hours. The ${ }^{60} \mathrm{Co}$ sources when these plans were developed were 2.5 years old.

An important limitation of our study is the reliability of DTI-based tractography. Further studies of validation of tractography with electrophysiology are necessary. A recent multicenter study reported the limitations in clinical use of tractography for neurosurgical decision making, based on great inter-algorithm variability. ${ }^{34}$ The fractional anisotropy threshold is a factor that could influence the reconstruction of tracts. ${ }^{39}$ Tractography may underestimate the fiber tracts, ${ }^{19}$ especially at lateral projections from the hand, face, and tongue. ${ }^{34}$ The tractography in this study also showed that difficulties occurred in reproducing fibers at lateral projections, although they were considered in $85 \%$ of cases to be excellent or good, according to the correlation between tractography, anisotropy, and conventional neuroanatomy.

\section{Conclusions}

Tractography is an important tool that needs to be used carefully, with the awareness that we are observing only a fraction of reality and depicting nondirectional fibers. ${ }^{42}$ The image fusion and its pitfalls also need to be taken into consideration when introducing multi-imaging processing and the reliability of targeting precision. DTI tractography is progressively being implemented in neurosurgery, ${ }_{16,24,36}$ with the opportunity of its validation when electrophysiology is possible. This progress in neuroimaging has to be incorporated into stereotactic surgery, ${ }^{12,17,38}$ especially in 
radiosurgery, which is completely dependent on exquisite quality imaging. The challenge is the standardization of the technique necessary to compare clinical studies across institutions. The routine use of DTI pyramidal tractography might be important to fine-tune GK-T planning.

\section{References}

1. Arai Y, Kano H, Lunsford LD, Novotny J Jr, Niranjan A, Flickinger JC, et al: Does the Gamma Knife dose rate affect outcomes in radiosurgery for trigeminal neuralgia? J Neurosurg 113 Suppl:168-171, 2010

2. Barkhoudarian G, Klochkov T, Sedrak M, Frew A, Gorgulho A, Behnke E, et al: A role of diffusion tensor imaging in movement disorder surgery. Acta Neurochir (Wien) 152:2089-2095, 2010

3. Behrens TE, Johansen-Berg H, Woolrich MW, Smith SM, Wheeler-Kingshott CA, Boulby PA, et al: Non-invasive mapping of connections between human thalamus and cortex using diffusion imaging. Nat Neurosci 6:750-757, 2003

4. Bryant JA, De Salles A, Cabatan C, Frysinger R, Behnke E, Bronstein J: The impact of thalamic stimulation on activities of daily living for essential tremor. Surg Neurol 59:479-485, 2003

5. Campbell AM, Glover J, Chiang VL, Gerrard J, Yu JB: Gamma Knife stereotactic radiosurgical thalamotomy for intractable tremor: a systematic review of the literature. Radiother Oncol 114:296-301, 2015

6. Deoni SC, Josseau MJ, Rutt BK, Peters TM: Visualization of thalamic nuclei on high resolution, multi-averaged T1 and T2 maps acquired at 1.5 T. Hum Brain Mapp 25:353-359, 2005

7. Deoni SC, Rutt BK, Parrent AG, Peters TM: Segmentation of thalamic nuclei using a modified k-means clustering algorithm and high-resolution quantitative magnetic resonance imaging at 1.5 T. Neuroimage 34:117-126, 2007

8. Duma CM, Jacques DB, Kopyov OV, Mark RJ, Copcutt B, Farokhi HK: Gamma Knife radiosurgery for thalamotomy in parkinsonian tremor: a five-year experience. J Neurosurg 88:1044-1049, 1998

9. Fowler JF: 21 years of biologically effective dose. Br J Radiol 83:554-568, 2010

10. Friehs GM, Park MC, Goldman MA, Zerris VA, Norén G, Sampath P: Stereotactic radiosurgery for functional disorders. Neurosurg Focus 23(6):E3, 2007

11. Gorgulho A, De Salles AAF, Frighetto L, Benhke E: Incidence of hemorrhage related to electrophysiological studies performed using macroelectrodes and microelectrodes in functional surgery. J Neurosurg 102:888-896, 2005

12. Gorgulho AA, Shields DC, Malkasian D, Behnke E, Desalles AAF: Stereotactic coordinates associated with facial musculature contraction during high-frequency stimulation of the subthalamic nucleus. J Neurosurg 110:1317-1321, 2009

13. Higuchi Y, Matsuda S, Serizawa T: Gamma Knife radiosurgery in movement disorders: indications and limitations. Mov Disord [epub ahead of print], 2016

14. Hyam JA, Owen SL, Kringelbach ML, Jenkinson N, Stein JF, Green AL, et al: Contrasting connectivity of the ventral intermedius and ventralis oralis posterior nuclei of the motor thalamus demonstrated by probabilistic tractography. Neurosurgery 70:162-169, 2012

15. Johansen-Berg H, Behrens TE, Sillery E, Ciccarelli O, Thompson AJ, Smith SM, et al: Functional-anatomical validation and individual variation of diffusion tractographybased segmentation of the human thalamus. Cereb Cortex 15:31-39, 2005

16. Kamada K, Todo T, Masutani Y, Aoki S, Ino K, Takano T, et al: Combined use of tractography-integrated functional neuronavigation and direct fiber stimulation. J Neurosurg 102:664-672, 2005
17. Kamada K, Todo T, Ota T, Ino K, Masutani Y, Aoki S, et al: The motor-evoked potential threshold evaluated by tractography and electrical stimulation. J Neurosurg 111:785-795, 2009

18. Kihlström L, Hindmarsh T, Lax I, Lippitz B, Mindus P, Lindquist C: Radiosurgical lesions in the normal human brain 17 years after Gamma Knife capsulotomy. Neurosurgery 41:396-402, 1997

19. Kinoshita M, Yamada K, Hashimoto N, Kato A, Izumoto S, Baba T, et al: Fiber-tracking does not accurately estimate size of fiber bundle in pathological condition: initial neurosurgical experience using neuronavigation and subcortical white matter stimulation. Neuroimage 25:424-429, 2005

20. Kondziolka D, Ong JG, Lee JY, Moore RY, Flickinger JC, Lunsford LD: Gamma Knife thalamotomy for essential tremor. J Neurosurg 108:111-117, 2008

21. Kooshkabadi A, Lunsford LD, Tonetti D, Flickinger JC, Kondziolka D: Gamma Knife thalamotomy for tremor in the magnetic resonance imaging era. J Neurosurg 118:713-718, 2013

22. Lefranc M, Carron R, Regis J: Prelemniscal radiations: a new reliable landmark of the thalamic nucleus ventralis intermedius location. Stereotact Funct Neurosurg 93:400-406, 2015

23. Lehman JF, Greenberg BD, McIntyre CC, Rasmussen SA, Haber SN: Rules ventral prefrontal cortical axons use to reach their targets: implications for diffusion tensor imaging tractography and deep brain stimulation for psychiatric illness. J Neurosci 31:10392-10402, 2011

24. Lemaire JJ, Frew AJ, McArthur D, Gorgulho AA, Alger JR, Salomon N, et al: White matter connectivity of human hypothalamus. Brain Res 1371:43-64, 2011

25. Lemaire JJ, Nezzar H, Sakka L, Boirie Y, Fontaine D, Coste A, et al: Maps of the adult human hypothalamus. Surg Neurol Int 4 (Suppl 3):S156-S163, 2013

26. Lim SY, Hodaie M, Fallis M, Poon YY, Mazzella F, Moro E: Gamma Knife thalamotomy for disabling tremor: a blinded evaluation. Arch Neurol 67:584-588, 2010

27. Makris N, Rathi Y, Mouradian P, Bonmassar G, Papadimitriou G, Ing WI, et al: Variability and anatomical specificity of the orbitofrontothalamic fibers of passage in the ventral capsule/ventral striatum (VC/VS): precision care for patientspecific tractography-guided targeting of deep brain stimulation (DBS) in obsessive compulsive disorder (OCD). Brain Imaging Behav [epub ahead of print], 2015

28. Mathieu D, Kondziolka D, Niranjan A, Flickinger J, Lunsford LD: Gamma Knife thalamotomy for multiple sclerosis tremor. Surg Neurol 68:394-399, 2007

29. Mobin F, De Salles AAF, Behnke EJ, Frysinger R: Correlation between MRI-based stereotactic thalamic deep brain stimulation electrode placement, macroelectrode stimulation and clinical response to tremor control. Stereotact Funct Neurosurg 72:225-232, 1999

30. Ohye C, Higuchi Y, Shibazaki T, Hashimoto T, Koyama T, Hirai T, et al: Gamma Knife thalamotomy for Parkinson disease and essential tremor: a prospective multicenter study. Neurosurgery 70:526-536, 2012

31. Okun MS, Stover NP, Subramanian T, Gearing M, Wainer BH, Holder CA, et al: Complications of Gamma Knife surgery for Parkinson disease. Arch Neurol 58:1995-2002, 2001

32. Pinheiro JC, Bates DM: Mixed-Effects Models in S and S-PLUS. New York: Springer, 2000, pp 100, 461

33. Pouratian N, Zheng Z, Bari AA, Behnke E, Elias WJ, Desalles AA: Multi-institutional evaluation of deep brain stimulation targeting using probabilistic connectivity-based thalamic segmentation. J Neurosurg 115:995-1004, 2011

34. Pujol S, Wells W, Pierpaoli C, Brun C, Gee J, Cheng G, et al: The DTI challenge: toward standardized evaluation of diffu- 
sion tensor imaging tractography for neurosurgery. J Neuroimaging 25:875-882, 2015

35. Sedrak M, Gorgulho A, Bari A, Behnke E, Frew A, Gevorkyan I, et al: Diffusion tensor imaging (DTI) and colored fractional anisotropy (FA) mapping of the subthalamic nucleus (STN) and the globus pallidus interna (GPi). Acta Neurochir (Wien) 152:2079-2084, 2010

36. Sedrak M, Gorgulho A, De Salles AF, Frew A, Behnke E, Ishida $\mathrm{W}$, et al: The role of modern imaging modalities on deep brain stimulation targeting for mental illness. Acta Neurochir Suppl 101:3-7, 2008

37. Sedrak M, Gorgulho A, Frew A, Behnke E, DeSalles A, Pouratian N: Diffusion tensor imaging and colored fractional anisotropy mapping of the ventralis intermedius nucleus of the thalamus. Neurosurgery 69:1124-1130, 2011

38. Shields DC, Gorgulho A, Behnke E, Malkasian D, DeSalles AA: Contralateral conjugate eye deviation during deep brain stimulation of the subthalamic nucleus. J Neurosurg 107:37-42, 2007

39. Taoka T, Morikawa M, Akashi T, Miyasaka T, Nakagawa H, Kiuchi K, et al: Fractional anisotropy-threshold dependence in tract-based diffusion tensor analysis: evaluation of the uncinate fasciculus in Alzheimer disease. AJNR Am J Neuroradiol 30:1700-1703, 2009

40. Vaughan P, Hampshire A, Soanes T, Kemeny A, Radatz M, Rowe J, et al: The clinical application of plugging patterns for the Leksell Gamma Knife. J Neurosurg 97 (5 Suppl):579-581, 2002

41. Witjas T, Carron R, Krack P, Eusebio A, Vaugoyeau M, Hariz M, et al: A prospective single-blind study of Gamma Knife thalamotomy for tremor. Neurology 85:1562-1568, 2015

42. Yamada K, Sakai K, Akazawa K, Yuen S, Nishimura T: MR tractography: a review of its clinical applications. Magn Reson Med Sci 8:165-174, 2009

43. Young RF, Jacques S, Mark R, Kopyov O, Copcutt B, Posewitz A, et al: Gamma Knife thalamotomy for treatment of tremor: long-term results. J Neurosurg 93 (Suppl 3):128135,2000

44. Young RF, Li F, Vermeulen S, Meier R: Gamma Knife thala- motomy for treatment of essential tremor: long-term results. J Neurosurg 112:1311-1317, 2010

45. Young RF, Shumway-Cook A, Vermeulen SS, Grimm P, Blasko J, Posewitz A, et al: Gamma Knife radiosurgery as a lesioning technique in movement disorder surgery. J Neurosurg 89:183-193, 1998

\section{Disclosures}

The authors report no conflict of interest concerning the materials or methods used in this study or the findings specified in this paper.

\section{Author Contributions}

Conception and design: all authors. Acquisition of data: De Salles, Gomes, Gorgulho, Lopez, Saraiva, Passaro, Siqueira. Analysis and interpretation of data: De Salles, Gomes, Gorgulho, Lopez, Damiani, BP Salvajoli. Drafting the article: De Salles, Gomes. Critically revising the article: De Salles, Gomes, Gorgulho, Lopez, Damiani. Reviewed submitted version of manuscript: De Salles, Gomes, Gorgulho, Saraiva, Damiani, JV Salvajoli, Siqueira, BP Salvajoli. Statistical analysis: Damiani. Administrative/technical/material support: De Salles. Study supervision: De Salles, Gomes.

\section{Supplemental Information \\ Previous Presentations}

Portions of this work were presented at the 18th Annual Leksell Gamma Knife Society Meeting, Amsterdam, The Netherlands, May 15-19, 2016.

\section{Correspondence}

Antonio De Salles, Rua Eliseu Guilherme 130 - $3^{0}$ Andar-Neurociência, São Paulo, SP 04004-030, Brazil.email: a.desalles@ yahoo.com. 